\title{
Action Potential Propagation in Dendrites of Rat Mitral Cells In Vivo
}

\author{
F. Debarbieux, E. Audinat, and S. Charpak \\ Laboratoire de Neurophysiologie, Institut National de la Santé et la Recherche Médicale, EPI 0002, Centre National de la Recherche Scientifique, FRE 2500, \\ Ecole Supérieure de Physique et Chimie Industrielles de la Ville de Paris, 75231 Paris, France
}

Odors evoke $\beta$ - $\gamma$ frequency field potential oscillations in the olfactory systems of awake and anesthetized vertebrates. In the rat olfactory bulb, these oscillations reflect the synchronous discharges of mitral cells that result from both their intrinsic membrane properties and their dendrodendritic interactions with local inhibitory interneurons. Activation of dendrodendritic synapses is purportedly involved in odor memory and odor contrast enhancement. Here we investigate in vivo to what extent action potentials propagate to remote dendrodendritic sites in the entire dendritic tree and if this propagation is changed during discharges at $40 \mathrm{~Hz}$. By combining intracellular recording and two-photon microscopy imaging of intracellular calcium $\left(\left[\mathrm{Ca}^{2+}\right]_{\mathrm{i}}\right)$, we show that in remote branches of the apical tuft and basal dendrites, transient $\mathrm{Ca}^{2+}$ changes are triggered by single sodium action potentials. Neither the amplitude of these $\mathrm{Ca}^{2+}$ transients nor that of action potentials obtained from intradendritic recordings showed a significant attenuation as a function of the distance from the soma. Calcium channel density seemed homogeneous; however, propagating action potentials occasionally failed to trigger a $\mathrm{Ca}^{2+}$ transient at a site closer to the soma whereas it did farther. This suggests that measurements of calcium transients underestimate the occurrence of sodium action potentials. During $40 \mathrm{~Hz}$ bursts of action potentials, $\left[\mathrm{Ca}^{2+}\right]_{\mathrm{i}}$ increases with the number of action potentials in all dendritic compartments. These results suggest that the presence of release sites in dendrites is accompanied by an "axonal-like behavior" of the entire dendritic tree of mitral cells, including their most distal dendritic branches.

Key words: olfactory bulb; two-photon microscopy; oscillation; calcium signaling; rat; intracellular recording

\section{Introduction}

Neuronal dendrites do more than passively integrate and convey synaptic currents to a spike-initiating zone near the soma (for review, see Shepherd, 1999; Hausser et al., 2000). In many neurons, voltage-dependent regenerative $\mathrm{Na}^{+}$and $\mathrm{Ca}^{2+}$ currents participate in transferring excitatory synaptic inputs from distal dendrites to the soma and axon hillock or into other dendritic branches. Furthermore, $\mathrm{Na}^{+}$-dependent action potentials initiated near the soma backpropagate to varying extents into dendrites, depending on the neuronal type, the previous history of activation of the neuron, or the neuromodulatory inputs (Colbert et al., 1997; Hoffman et al., 1997; Stuart et al., 1997; Tsubokawa and Ross, 1997). These backpropagating spikes have been proposed to implement numerous processes, including coincidence detection for synaptic plasticity (Markram et al., 1997), amplification of synaptic currents (Larkum et al., 1999), potentiation of $\mathrm{Ca}^{2+}$ influx through NMDA receptors (Schiller et al., 1998), metabotropic glutamate receptor-mediated $\mathrm{Ca}^{2+}$ release

Received Jan. 29, 2003; revised April 7, 2003; accepted April 15, 2003.

This work was support by the Institut National de la Santé et de la Recherche Médicale, the Ministère de I'Education Nationale de la Recherche et de la Technologie, the Centre National de la Recherche Scientifique, the Fondation pour la Recherche Médicale (ICP 20001222 128), and the European Union (QL G3-CT-2000-00934). We thank J. Mertz and M. Oheim for comments on this manuscript.

Correspondence should be addressed to Serge Charpak, Laboratoire de Neurophysiologie, Institut National de la Santé et la Recherche Médicale, EPI 0002, Centre National de la Recherche Scientifique, FRE 2500, Ecole Supérieure de Physique et Chimie Industrielles de la Ville de Paris, 10 rue Vauguelin, 75231 Paris, France. E-mail: serge.charpak@espci.fr.

Copyright $\odot 2003$ Society for Neuroscience $\quad$ 0270-6474/03/235553-08\$15.00/0 from internal stores (Nakamura et al., 1999), and evoking release (Zilberter et al., 1999; Zilberter, 2000).

In the olfactory bulb, mitral cell dendrites establish reciprocal dendrodendritic synapses with periglomerular and granular inhibitory cells (Rall et al., 1966). Activation of these dendritic synapses mediates both recurrent inhibition and lateral inhibition (Mori and Takagi, 1978; Jahr and Nicoll, 1980), two synaptic processes thought to be involved in odor memory (Kaba et al., 1994) and odor contrast enhancement (Yokoi et al., 1995), respectively. Moreover, glutamate release at these sites also promotes self-excitation (Aroniadou-Anderjaska et al., 2000; Friedman and Strowbridge, 2000; Salin et al., 2001). Thus, characterization of action potential propagation to dendrodendritic sites and modulation of the propagation by local synaptic interactions is important to determine the role of mitral cells in the control of bulbar network activity. In vitro, dual electrophysiological recording and imaging experiments have provided clear evidence for dendritic $\mathrm{Na}^{+}$-dependent action potentials, locally generated or backpropagating in apical dendrites of mitral cells (Bischofberger and Jonas, 1997; Chen et al., 1997, 2002; Isaacson and Strowbridge, 1998), and have also demonstrated the basic physiology of the mitral to granule cell reciprocal synapse (Isaacson and Strowbridge, 1998; Kirillova and Lin, 1998; Schoppa et al., 1998; Chen et al., 2000; Isaacson, 2001) and of mitral cell selfexcitation (Aroniadou-Anderjaska et al., 2000; Friedman and Strowbridge, 2000; Salin et al., 2001). These initial studies, however, did not investigate the mechanisms that could regulate the 
extent of dendritic propagation in the apical tuft or in basal dendrites. Combining patch recording and imaging in basal dendrites in vitro, Margrie et al. (2001) showed that propagation of single spikes is decremental with distance and that trains of action potentials are required to reach the remote part of the dendrites. It implied that basal dendrites consist of several compartments that would be differentially involved with activity. These results, however, were later questioned in in vitro studies which showed that propagation of action potentials can occur distally in basal dendrites and is modulated by inhibition (Lowe, 2002; Xiong and Chen, 2002).

In vivo, the "neuron environment" is different from that in an in vitro slice, e.g., spontaneous and miniature excitatory and inhibitory synaptic potentials will influence membrane input resistance, voltage-gated channel activation rates, and thus dendritic action potential initiation and backpropagation (Pare et al., 1998; Svoboda et al., 1999). In vivo measurements of dendritic function in the intact brain are thus needed to complement the detailed in vitro studies. Combining intracellular recordings with two-photon laser scanning microscopy (TPLSM) (Denk et al., 1990) imaging of intracellular calcium $\left[\mathrm{Ca}^{2+}\right]_{\mathrm{i}}$ in vivo, we have demonstrated previously that single sodium-dependent action potentials propagate in the proximal parts of apical and basal dendrites of mitral cells (Charpak et al., 2001). In the present study, we analyze in vivo how single action potentials and $40 \mathrm{~Hz}$ bursts of action potentials propagate in the entire dendritic tree of rat mitral cells. We find that each action potential can participate in remote intraglomerular and lateral dendritic synaptic interactions.

Some of these data have been presented previously in preliminary form (Debarbieux et al., 2001).

\section{Materials and Methods}

In vivo electrophysiology and odor stimulations. Wistar rats, postnatal day $30-45$, were anesthetized with urethane $(1.5 \mathrm{gm} / \mathrm{kg}$, i.p.) and held in a standard stereotaxic apparatus with ear bars. Atropine $(0.5 \mathrm{mg} / \mathrm{kg}$, i.p. $)$ was injected at the onset of anesthesia and supplemented at approximately hourly intervals at $0.1 \mathrm{mg} / \mathrm{kg}$ to reduce bronchial secretion. In control experiments performed without atropine injection, we did not observe any change in the probability of calcium transient detection during backpropagation of single action potentials (all data were pooled). In each experiment, the posterior cisterna was drained. A craniotomy was performed above one bulb hemisphere and the dura was removed. A recording micropipette was then positioned at the surface of the bulb, a glass coverslip was placed on a metal frame attached to the skull, and the space below the glass was filled with a $3.5 \%$ Agar solution. The temperature of the animal was maintained at $36-37^{\circ} \mathrm{C}$. Borosilicate glass micropipettes were filled with a solution of $3 \mathrm{~mm}$ Oregon Green-1BAPTA in $2 \mathrm{~m} \mathrm{~K}$-acetate, $\mathrm{pH}$ 7.2. The dye was injected with a continuous hyperpolarizing current of $\sim 0.5 \mathrm{nA}$ for $10-30 \mathrm{~min}$. Electrophysiological signals recorded with a Neurodata amplifier (Cygnus Technology) were digitized and stored on a PC (Digidata 1200A, Clampex 8; Axon Instruments). In addition, electrophysiological data were simultaneously acquired and synchronized to the images with custom LabView-based software at sampling rate of $5-10 \mathrm{kHz}$ with 12 bit resolution. Odors (Isoamyl acetate or propionic acid) were applied for a duration of $2 \mathrm{sec}$ with a custom-built olfactometer. Teflon tubing was used from the odor reservoir to the nose.

In vivo two-photon imaging. Oregon Green-1 fluorescence was excited and imaged using a custom-built two-photon laser scanning microscope. An $830 \mathrm{~nm}$ excitation beam from a femtosecond pulsed laser (Coherent; $5 \mathrm{~W}$ pump) was focused onto filled neurons using a $63 \times$ Leica water immersion objective. Galvanometric scanning (Cambridge Technology, Cambridge, MA) controlled by home-built electronics and software (LabView) were used to obtain repetitive single line scans at rates between 300 and 3000 lines per second or images from subregions of the field of view at rates up to 20 per second. A background fluorescence value was obtained by averaging pixels from an unstained region of the tissue. Rectangular zones of interest in the image containing dye-filled structures were chosen for analysis. Normalized fluorescence changes were calculated as $\Delta F / F=(F-F 0) /(F 0)$, where $F$ is the background corrected average fluorescence signal within the measurement box and $F 0$ is the background corrected intensity averaged over five frames at the start of a sequence. Values of $\Delta F / F$ are given as mean \pm SEM.

To compare the failure rate of the $\mathrm{Ca}^{2+}$ transients of two adjacent sites recorded simultaneously with a single line scan on the same dendritic branch (see Fig. 3), traces of $\Delta F / F$ were first zeroed relative to the $50 \mathrm{msec}$
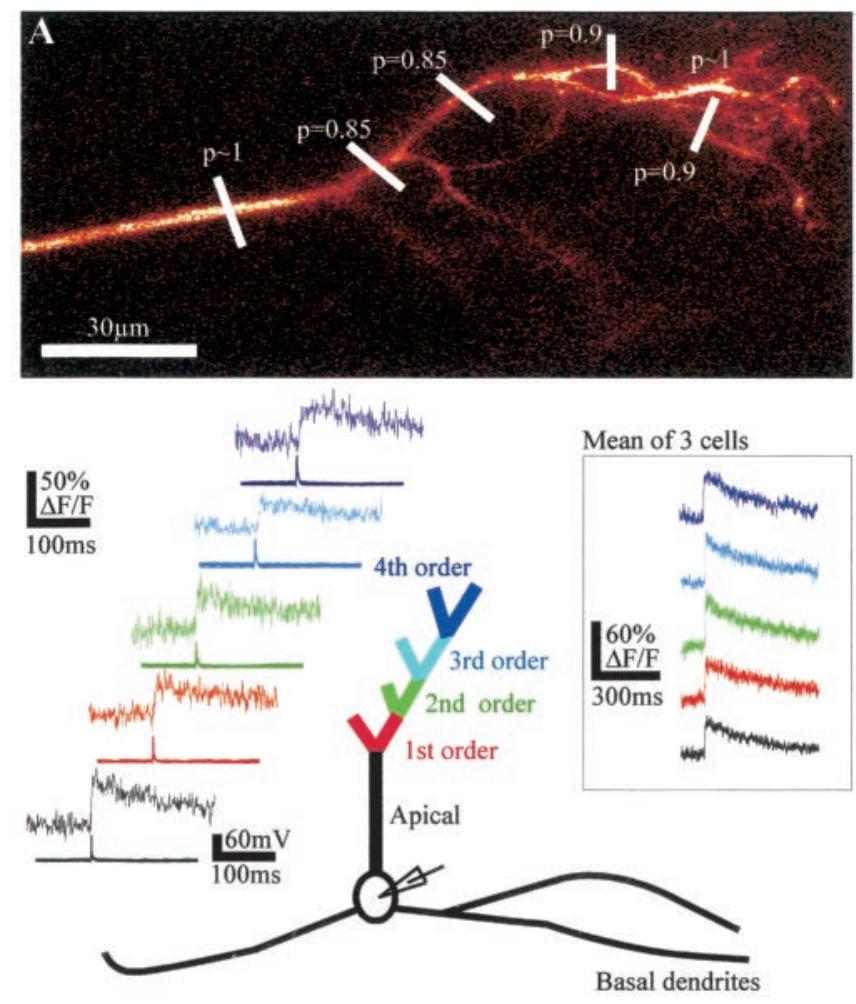

B1

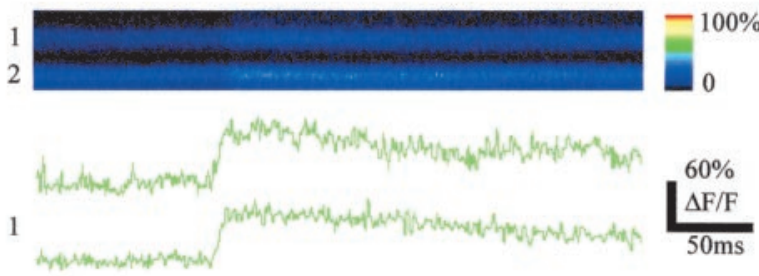

B2

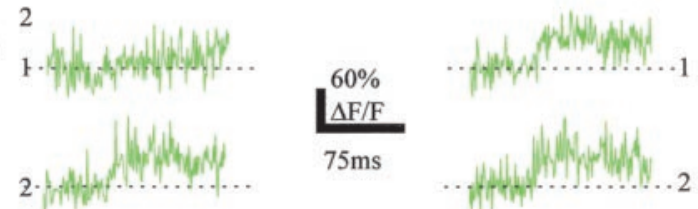

Figure 1. Single action potentials backpropagate reliably in remote branches of the apical dendrite. $A$, Top, morphology of a mitral cell tuft. The recording electrode was placed in the soma. The detection probabilities of fast $\mathrm{Ca}^{2+}$ transients evoked by single action potentials are indicated at the levels where the line scan recordings were done. Bottom, Averages $(n=30)$ of fast $\mathrm{Ca}^{2+}$ transients (top traces) triggered by single action potentials (bottom traces) in branches of successive order represented by different colors. Inset, Mean of three cells. $B, \mathrm{Ca}^{2+}$ transients can occur independently in two branches (second order) originating from the same branch and recorded simultaneously. $B 1$, Single action potentials evoke transient changes in fluorescence $(F, X=$ time, $y=$ distance scanned) seen as color changes in the two branches (top panel) or as changes in $\Delta F / F$ (bottom two traces). $B 2$, Traces on the left show an example of a $\mathrm{Ca}^{2+}$ failure occurring in branch 1 and not in branch 2. Traces on the right show single $\mathrm{Ca}^{2+}$ transients recorded simultaneously in branches 1 and 2 . 


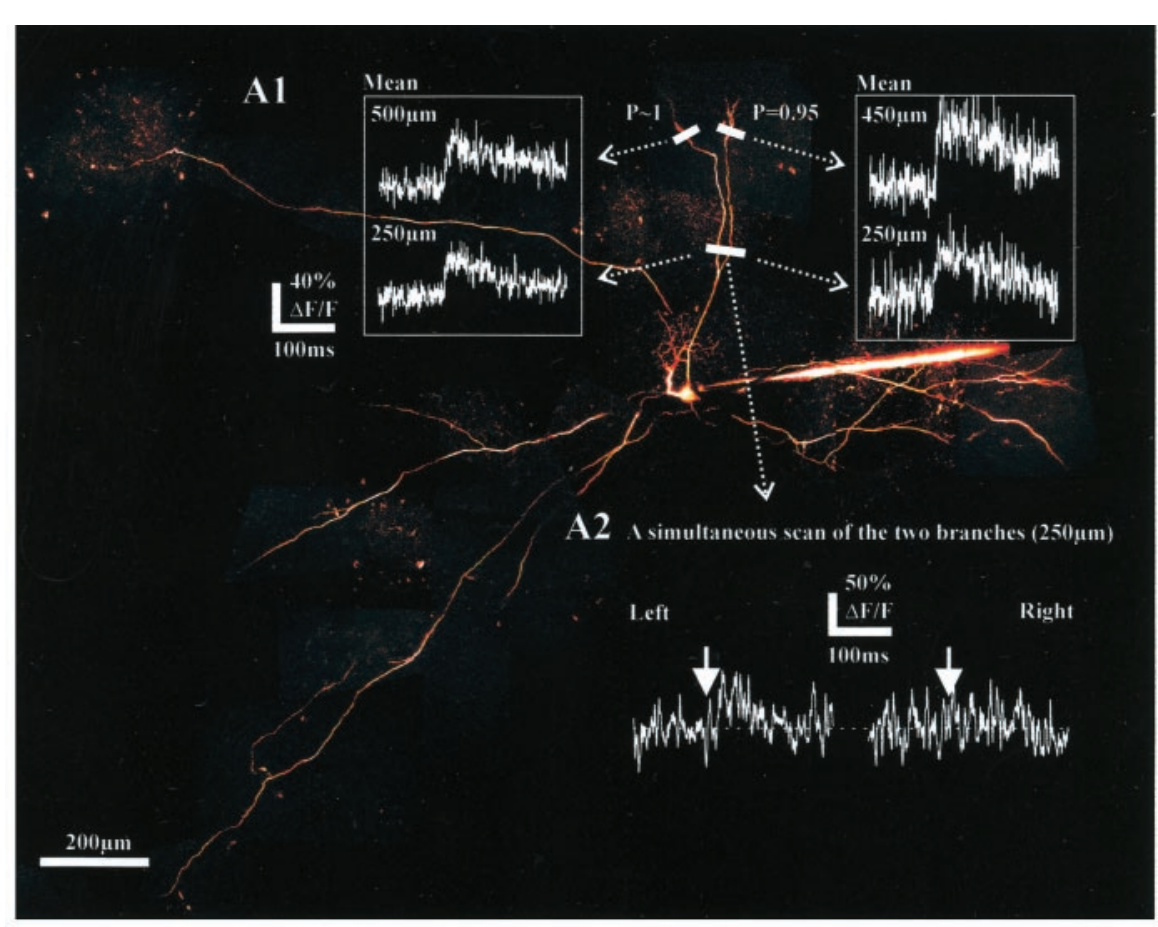

B Mean of 4 paired cells
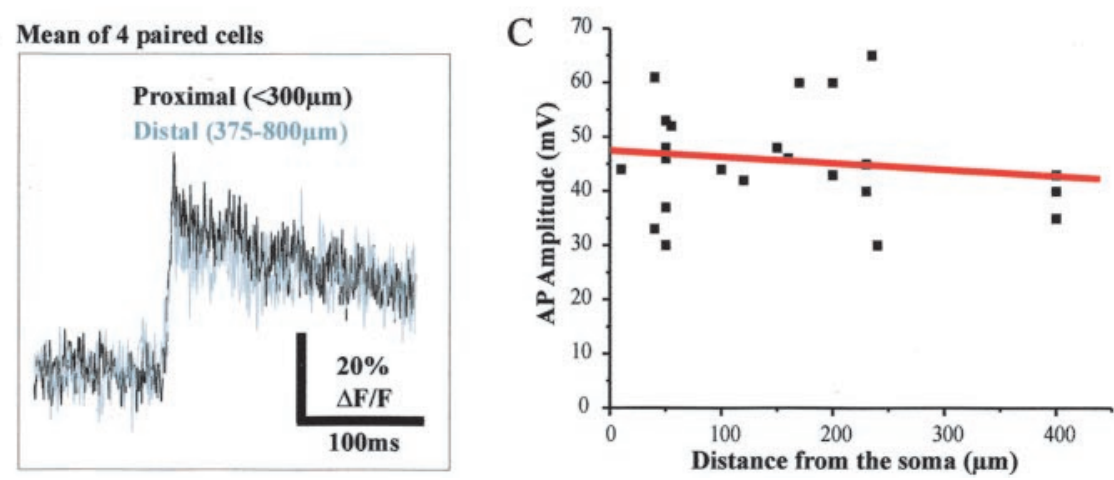

Figure 2. Single action potentials backpropagate in remote sites of the basal dendrites. $A 1, \mathrm{Ca}^{2+}$ transients were detected in two basal branches (top) in response to single action potentials. The probability of detection at the most distal sites is indicated at the levels where the line scans were done (450 and $500 \mu \mathrm{m}$ from the soma). Note that the average $\mathrm{Ca}^{2+}$ transients $(n=30)$ recorded proximally $(250 \mu \mathrm{m})$ and distally $(\sim 500 \mu \mathrm{m})$ in the two basal branches were very similar. A2 illustrates a case in which a failure occurred only in the right proximal branch. $B$, Mean values of the $\mathrm{Ca}^{2+}$ transients observed proximally and distally. In one case, the signal was measured at $950 \mu \mathrm{m}$ from the soma. C, The amplitude of sodium action potentials did not significantly decrease with the distance from the soma at which the recording electrode was placed in the basal dendrite.

preceding each evoked action potential (baseline), and the integral of $\Delta F / F$ was calculated over $50 \mathrm{msec}$ after the peak of the action potential. These values were used to construct histograms that were compared with histograms of the noise obtained by measuring the integral of $\Delta F / F$ over the $50 \mathrm{msec}$ preceding the baseline region. We considered as failures all the values of $\Delta F / F$ that were less than or equal to twice the SD of the noise distribution.

\section{Results}

Single sodium action potentials backpropagate to remote sites of the apical tuft

Intracellular recordings $(n=83)$ with stable membrane potentials of $-55 \mathrm{mV}$ or greater were obtained from mitral and tufted cells. The location of the recording pipette was obtained by TPLSM imaging of the micropipette tip. Approximately $70 \%$ $(n=61)$ of the cells were impaled in a dendrite rather than in the soma. Because we were aiming at secondary dendrites, only onethird of these dendritic recordings were from apical dendrites.
The primary dendrite of mitral cells extends over $200-400 \mu \mathrm{m}$ in the direction of the glomerulus where it ends in a tuft of branches. Measurements of calcium dynamics with TPLSM in vivo have demonstrated that dendritic $\mathrm{Ca}^{2+}$ transients can be used as markers of sodium action potentials (Svoboda et al., 1997, 1999; Helmchen et al., 1999). Using this approach, we analyzed the propagation of sodium spikes along the apical trunk and the tuft branches $(n=7$ cells; three to six sites per cell). Action potentials were evoked with brief depolarizing current pulses (4-8 msec), and coincident $\mathrm{Ca}^{2+}$ transients were detected with a very high probability ( $p$ ranged from 0.6 to 1 ; mean \pm SEM $=$ $0.91 \pm 0.03 ; n=15-30$ action potentials at each recording site), even in the most distal part of the dendritic tuft. The high probability was maintained independently of the number of branching points (Fig. $1 A$ ). In three cells in which $\mathrm{Ca}^{2+}$ responses were analyzed in five successive sites (from the apical trunk to branches of the fourth order), the average amplitude of $\mathrm{Ca}^{2+}$ transients, including detection failures, ranged from 31 to $47 \% \Delta F / F$ (Fig. $1 A$, inset). The differences in the mean amplitudes that included failures could reflect the differences in the probability of failures, in the amplitude of individual $\mathrm{Ca}^{2+}$ transients, in the diameter of dendritic processes (a "surface/volume" effect), and in variations in the ability of action potentials to trigger $\mathrm{Ca}^{2+}$ transients (see below). Figure $1 B$ shows a case in which the slight difference in the mean values of $\mathrm{Ca}^{2+}$ transients observed in two daughter branches issued from the same branch (56 and $69 \% \Delta F / F$ for branches 1 and 2 , respectively) (Fig. $1 B 1$ ) resulted from differences in both the probability of failure $\left(p_{1}=0, p_{2}=0.2\right)$ and the average value of individual $\mathrm{Ca}^{2+}$ transients $(56$ and $88 \% \Delta F / F$ for branches 1 and 2 , respectively) measured in the absence of failure. Taken together, these results suggest that action potentials propagate with a very high reliability throughout the entire tuft of mitral cells, independently of the distance from the soma or the number of branching points.

\section{Single sodium action potentials backpropagate to remote sites of basal dendrites}

Basal dendrites extend over $\sim 1 \mathrm{~mm}$ laterally in the olfactory bulb. Whether single action potentials actively propagate to the most distal portions of the basal dendrites in vivo is unknown. We found that single action potentials evoked with brief depolarizing current pulses $(4-8 \mathrm{msec})$ induced coincident $\mathrm{Ca}^{2+}$ transients in basal dendrites with a very high probability (Fig. $2 A$ ), even at distances of $950 \mu \mathrm{m}$. No difference in average value of the $\mathrm{Ca}^{2+}$ transients was observed when $\mathrm{Ca}^{2+}$ signals were recorded proximally $(<300 \mu \mathrm{m})$ or distally $(>375 \mu \mathrm{m}$, up to $950 \mu \mathrm{m} ; n=7$ 
cells) (Fig. $2 A 1, B)$. The probability of $\mathrm{Ca}^{2+}$ transient detection was high ( $p$ ranged from 0.6 to 1 ; mean \pm SEM $=0.87 \pm 0.04$ ). In support of the data obtained with two-photon imaging, intracellular recordings in the lateral dendrites revealed that the action potential size did not decrease significantly over a distance of 400 $\mu \mathrm{m}$ from the soma (Fig. $2 C$ ). The average size of action potentials, however, was small ( $46 \pm 2 \mathrm{mV} ; n=23$ ), a value that we attribute to the difficulty of recording thin dendrites in vivo. Our results therefore suggest that action potentials propagate with a very high reliability all along the basal dendrites of mitral cells, independently of the distance from the soma.

In basal dendrites as in tufts (Fig. $1 B$ ), however, failures of $\mathrm{Ca}^{2+}$ transients could occasionally occur in one dendritic branch and not in another issued from the same branch (Fig. 2A2). This suggests that the action potential either did not propagate or did not trigger any $\mathrm{Ca}^{2+}$ signal locally. We therefore investigated whether $\mathrm{Ca}^{2+}$ transients were reliable detectors of sodium action potentials. Figure 3 shows the results of experiments during which two points of the same branch were recorded simultaneously using a line scan either in a tuft (Fig. $3 A$ ) or in a basal dendrite (Fig. 3B). As described above, the probability to detect dendritic $\mathrm{Ca}^{2+}$ transients during an evoked action potential was high at all recording sites. We occasionally could detect, however, $\mathrm{a} \mathrm{Ca}^{2+}$ transient at one site while an apparent failure occurred at the other site (Fig. $3 A, B 1$, bottom traces). This was not caused by the presence of $\mathrm{Ca}^{2+}$ channel hot spots because the mean values of $\mathrm{Ca}^{2+}$ transients recorded proximally were similar to those recorded distally (Fig. $3 A, B 1$, top traces). Failures were not correlated with the occurrence of IPSPs detected at the electrophysiological recording site (data not shown). Figure $3 B 2$ shows the distributions of the $\mathrm{Ca}^{2+}$ transient integrals (see Materials and Methods) obtained from the two simultaneously recorded sites from the basal dendrite of Figure 3B1. In this example, an equivalent number of apparent failures was detected at both recording sites. There was no correspondence, however, between the failures observed proximally and distally. Green boxes in the histograms of Figure 3B2 identify two trials during which failures of $\Delta F / F$ occurred at the site closer to the soma, whereas large $\mathrm{Ca}^{2+}$ transients were detected at the more distal recording site. This implies that action potentials reaching the farther site did not systematically trigger $\mathrm{Ca}^{2+}$ transients at the closer site. Similar results were obtained in the basal dendrites of three other cells. Therefore, $\mathrm{Ca}^{2+}$ transients are not perfect indicators of action potentials in vivo, and despite their high values, the probabilities of action potential propagation in the dendrites of mitral cells based on measurements of $\mathrm{Ca}^{2+}$ transients are thus underestimations.

\section{In vivo, mitral cells fire preferentially at frequencies in the $\boldsymbol{\beta}-\boldsymbol{\gamma}$ range}

The efficient backpropagation of single action potentials in the dendrites of mitral cells in vivo does not ensure that every action potential of a burst will backpropagate (Spruston et al., 1995; Tsubokawa and Ross, 1996, 1997). We thus aimed at determining the preferred frequency at which mitral cells fire during a natural sensory stimulation during urethane anesthesia and then tested the efficiency of action potential backpropagation at this frequency.

Odor stimulation evoked various types of excitatory, mixed excitatory/inhibitory, or inhibitory responses. Figure $4 \mathrm{~A}$ illustrates a case in which three cells were sequentially impaled, from right to left, in an apical dendrite (near the soma), in a soma, and finally in a basal dendrite. In the left cell, odor application evoked an excitatory response that was characterized by synaptic depolarizations locked to the respiratory cycle and on which were
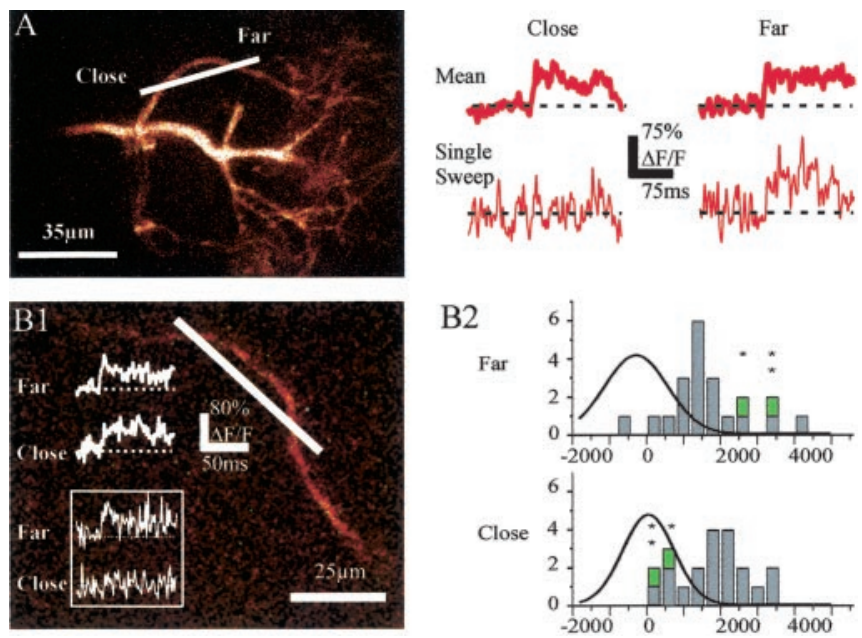

Figure 3. Measurements offast $\mathrm{Ca}^{2+}$ transients underestimate action potential backpropagation. $A, \mathrm{Ca}^{2+}$ signals were recorded simultaneously at two points from the same first-order branch of a tuft. Average $\mathrm{Ca}^{2+}$ transients (including failures) were similar at both locations (top traces). In some cases, however, an action potential did not trigger any $\mathrm{Ca}^{2+}$ signal at the site close to the soma whereas it did farther (bottom traces). $B 1, \mathrm{Ca}^{2+}$ signals were recorded simultaneously at two close points from the same branch of a basal dendrite. Average $\mathrm{Ca}^{2+}$ transients (including failures) were similar at both locations (top traces). 0 ccasionally, an action potential did not trigger any $\mathrm{Ca}^{2+}$ signal at the site closer to the soma whereas it did farther (bottom traces, inset). B2, Integral histograms of $\Delta F / F$ measured over $50 \mathrm{msec}$ after the action potential peak at the recording sites closer to (Close) and farther from (Far) the soma on the basal dendrite shown in B1. The green symbols (and the above stars) identify two cases of apparent failures at the proximal site and the corresponding calcium transients at the distal site. The superimposed curves correspond to the Gaussian fits of the noise integral distributions.

superimposed bursts of action potentials (Fig. $4 B$, left bottom trace); note that during odor stimulation, action potentials backpropagated in the secondary dendrite (left top trace). Such bursting behavior was also observed during the off response that followed odor-evoked inhibition in other cells. The initial hyperpolarization attributable to lateral inhibition was followed by $20-60 \mathrm{~Hz}$ bursts of action potentials (Fig. $4 \mathrm{~B}$, right trace). The intraburst frequency was usually in the $\beta-\gamma$ range: of 23 silent cells, the interspike interval distribution during odor stimulations could be fitted with two Gaussian curves in 15 cells, one centered on respiration rate and a second centered on $34 \pm 3.5$ $\mathrm{Hz}$ (mean \pm SEM). In the remaining eight cells, the interspike distributions required one or two additional Gaussian curves [centered respectively on $18 \pm 4(n=8)$ and $95 \pm 18 \mathrm{~Hz}(n=3)$ ]. These observations confirmed that in vivo, during odor stimulation, mitral cells fire bursts of action potentials in the $\beta-\gamma$ range (Mair, 1982; Hamilton and Kauer, 1985; Meredith, 1986; Wellis et al., 1989). Several parameters contribute to this bursting behavior. When we manipulated the membrane potential with depolarizing DC-current injections, we observed subthreshold membrane potential oscillations (Fig. $4 C$, white arrow) that induced bursts of action potentials with an interspike interval centered at $25 \mathrm{msec}$ (Fig. 4C). Thus, as shown in vitro (Chen and Shepherd, 1997; Desmaisons et al., 1999), the association of intrinsic membrane properties with recurrent inhibition stabilizes mitral cell discharge at a preferred frequency of " $40 \mathrm{~Hz}$." In vivo, however, olfactory inputs were able to re-entrain the generation of these bursts during a period of firing accommodation caused by a sustained depolarization (Fig. 4D). Several mechanisms thus participate to the generation of $40 \mathrm{~Hz}$ bursts during odor stimulation. We therefore tested how action potentials emitted at this frequency backpropagate in the apical tuft and basal dendrite of mitral cells. 


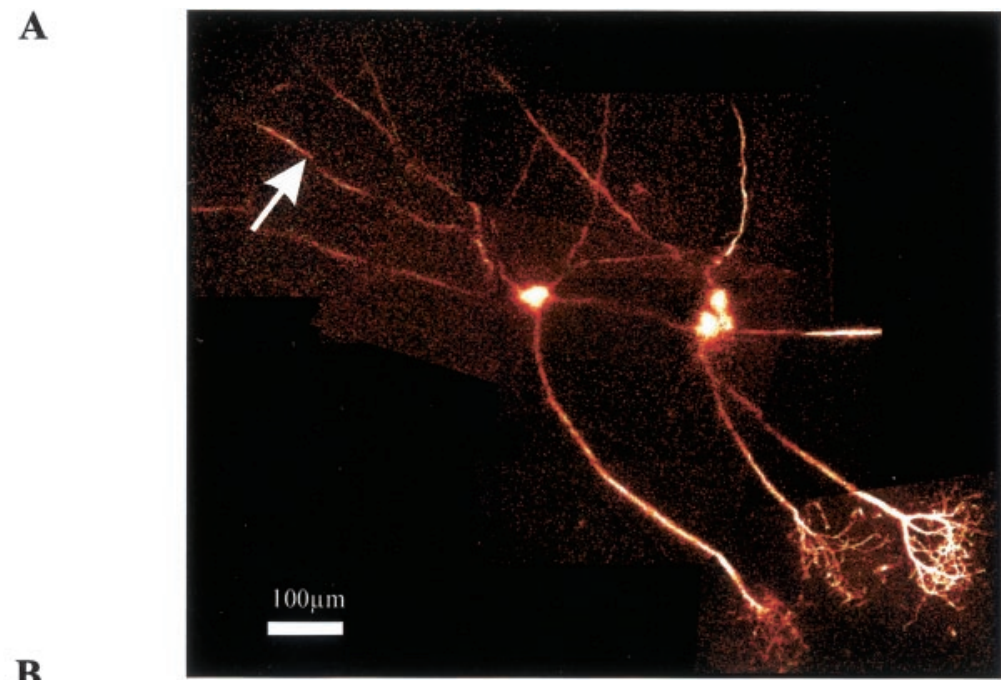

B

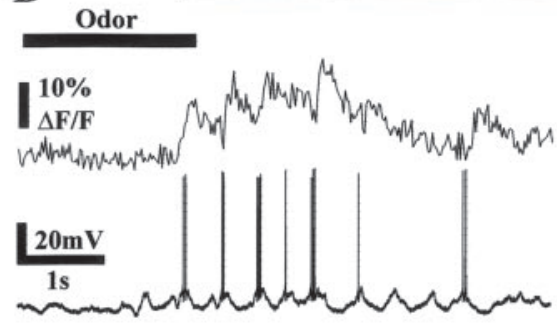

C
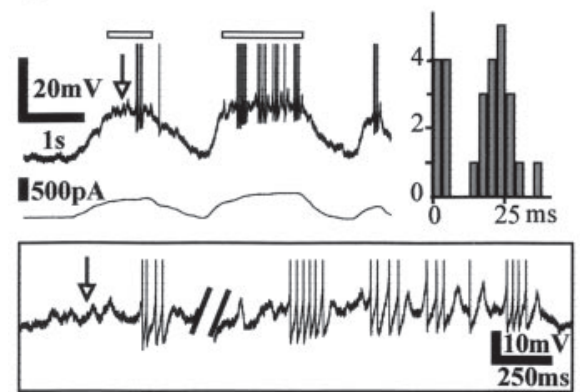

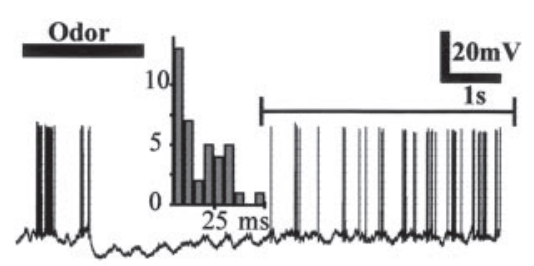

D

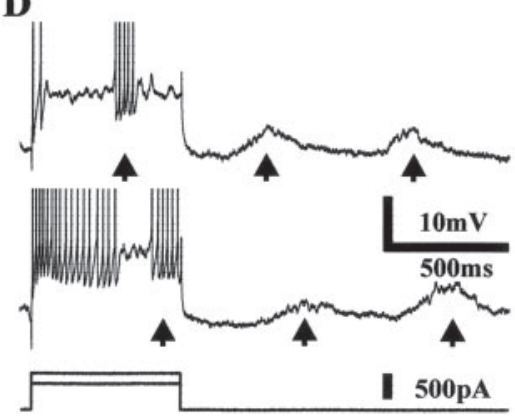

Figure 4. Mitral cells fire at $\beta$ - $\gamma$ frequencies. $A$, Three mitral cells were successively impaled in vivo, labeled with Oregon Green-1, and imaged with two-photon microscopy. $B$, The left cell was impaled in a basal dendrite and fired small high-frequency bursts of action potentials (left panel, bottom trace) during odor stimulation. Simultaneous recording of the $\mathrm{Ca}^{2+}$ signal (left panel, top trace, movie recording) from the basal dendrite site indicated by an arrow reveals that action potentials backpropagate during odor stimulation. The trace on the right shows the recording from another cell that exhibited bursts of action potentials after an initial odor-evoked inhibition. The distribution of the interspike intervals corresponded to firing frequencies in the $\beta$ - $\gamma$ range. C, Intrinsic membrane properties favor cell firing at $40 \mathrm{~Hz}$. Intracellular depolarizing DC current injections induced bursts of action potentials triggered by subthreshold membrane potential oscillations (white arrow) with an interspike interval centered on 25 msec. Right, Distribution of the interspike intervals measured over the parts of the trace indicated by the white rectangles. Inset, Enlargement of these two parts of the above trace indicated with white rectangles. D, Spontaneous synaptic inputs entrain burst discharges. Two depolarizing current pulses were applied to induce spike accommodation. Additional bursts of action potentials $(\sim 50 \mathrm{~Hz})$ were triggered by the synaptic inputs locked to air inhalations (arrows).

\section{$\beta-\gamma$ bursts of action potentials backpropagate to remote sites of the apical tuft}

Five brief current pulses were used to evoke bursts of action potentials in the $\beta-\gamma$ range (Fig. 5A). The bursts evoked $\mathrm{Ca}^{2+}$ increases that had amplitudes correlated to the number of action potentials. Figure $5 A$ illustrates the case of a fourth-order branch in which each $\mathrm{Ca}^{2+}$ transient coincident with one of the five spikes was almost similar and summation of fluorescence appeared linear. We then systematically compared the summation of fluorescence in the apical trunk and in one of its third- or fourth-order branches ( $n=12$ cells; 34 dendrites; interspike in- terval $=25 \mathrm{msec}$ ). To compare the $\mathrm{Ca}^{2+}$ increases, $\mathrm{Ca}^{2+}$ signals were superposed and normalized to the value of the $\mathrm{Ca}^{2+}$ increase induced by the first action potential. In the cell illustrated in Figure $5 B$, fluorescence summation was sublinear in both the apical trunk and the third-order branch. To quantify the sublinearity, we measured either $\Delta F \mathrm{n} / \Delta F 1$ (Fig. $5 C 2$ ) or $\Delta F \max / \Delta F 1, \Delta F \max$ corresponding to the total fluorescence change observed with five action potentials. Note that $\Delta F \max / \Delta F 1$ underestimated $\mathrm{Ca}^{2+}$ influxes because $\mathrm{Ca}^{2+}$ transients decayed between each spike. On average, summation sublinearity was observed at all sites $(\Delta F \max / \Delta F 1=3 \pm 0.2, n=8 ; 3.1 \pm 0.2$, $n=7 ; 3.3 \pm 0.2, n=7$ in the apical trunk, the third-order, and the fourth-order branches, respectively). Measurements of $\Delta F \mathrm{n} / \Delta F 1$ (Fig. 5C2) similarly showed a decrease of the $\Delta F 5 / \Delta F 1$ and $\Delta F 4 / \Delta F 1$. Because we used a high-affinity $\mathrm{Ca}^{2+}$ indicator $\left(K_{\mathrm{d}} \sim 200 \mathrm{nM}\right)$, dye saturation could account for part of the sublinearity that was observed (Cox et al., 2000; Maravall et al., 2000). In the example of Figure 5C, however, the fluorescence could still double in the apical trunk under stronger stimulation, as well as in the third-order branch (data not shown). Furthermore, because summation was also larger distally than proximally, an observation that suggests that action potentials did propagate farther from the soma, the summation sublinearity probably reflected a decrease in $\mathrm{Ca}^{2+}$ influx/action potential during the burst.

\section{$\beta-\gamma$ bursts of action potentials backpropagate to remote sites of the basal dendrites}

It has been suggested that high-frequency discharges would facilitate the propagation of action potentials in the basal dendrite. In our hands, $40 \mathrm{~Hz}$ bursts of action potentials evoked $\mathrm{Ca}^{2+}$ increases with an amplitude that was indeed correlated to the number of action potentials $(n=13$ cells, 24 dendrites) (Fig. 6). However, we did not observe any facilitation during the burst when we determined the fluorescence ratio $\Delta F \max / \Delta F 1$ proximally or distally. In fact, in four cells (named paired cells) in which the measurements were performed successively at two sites (proximal and distal) from the same dendrite, the fluorescence ratio $\Delta F \max / \Delta F 1$ showed similar sublinearity proximally and distally $(3.2 \pm 0.4$ and $3 \pm 0.4$ ) (Fig. $6 C$ ). Dye saturation could not explain the sublinearity because the fluorescence could still significantly increase on higher firing discharge (Fig. 6A). In these thin processes recorded in depth, individual traces were too noisy to allow the determination of the probability of $\mathrm{Ca}^{2+}$ transients for each action potential within a burst. However, considering the fact that single action potentials did not systematically trigger 
A

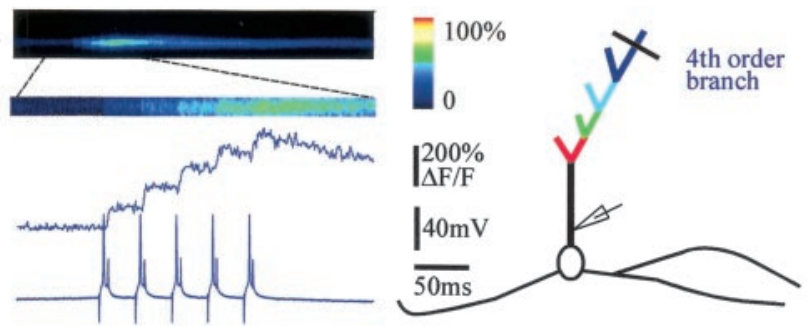

B

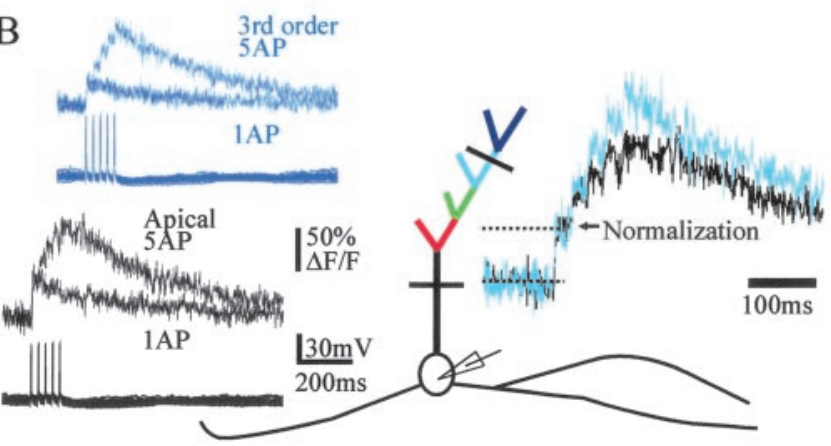

C1
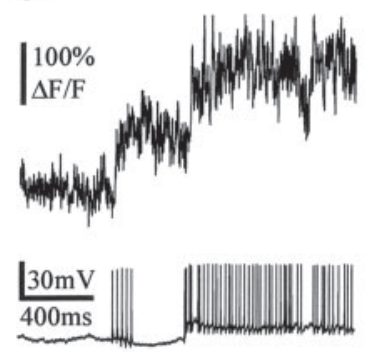

$\mathrm{C} 2$

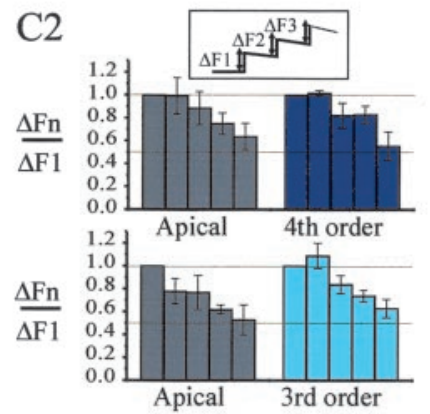

Figure 5. Bursts of action potentials backpropagate in the entire apical tuft. $A$, Left, Illustration of the protocol type used to mimic bursts of action potentials in the $\beta$ - $\gamma$ range, which induces a summation of $\mathrm{Ca}^{2+}$ transients (average of 18 bursts). Right, Schematic representation of the recorded mitral cell with the location of the recording pipette in the proximal part of the apical trunk and the line scan in a fourth-order branch. $B$, Another mitral cell recorded with an intracellular pipette placed in the soma. Left, Superpositions of $\mathrm{Ca}^{2+}$ signals evoked by one and five action potentials (interspike interval $=25 \mathrm{msec}$ ) in the apical trunk and in a third-order branch. Right, Superposition of the traces obtained with five action potentials at both locations and normalized to the first $\mathrm{Ca}^{2+}$ transients. Note that summation of fluorescence was sublinear in the apical trunk and in the third-order branch. (1, The sublinearity was not caused by saturation of the dye because the $\mathrm{Ca}^{2+}$ signal could still increase during higher firing frequency. $\mathrm{C2}$, Histograms of $\Delta F \mathrm{n} / \Delta F 1$ (inset) in the apical trunk and branches of the third (bottom histograms) and fourth (top histograms) order. In the two series, measurements were performed at two different sites of the same cell (apical trunk vs third-order branch, $n=3$, or apical trunk vs fourth-order branch, $n=3$ ).

$\mathrm{Ca}^{2+}$ transients (Fig. 3), we hypothesize that during the burst a decrease in the number of calcium channels activated per action potential, rather than failures of propagation, accounts for the sublinearity. In any case, $40 \mathrm{~Hz}$ discharges did not determine the distance at which active propagation occurs along the distal dendrite in vivo.

\section{Discussion}

In the present study, we show that in the anesthetized rat, dendritic propagation of sodium-dependent action potentials appears to be the default condition for the entire mitral cell dendritic tree. In all dendritic processes, the probability to detect a $\mathrm{Ca}^{2+}$ transient coincident with single action potential propagation was so high that one may consider, at first, that $\mathrm{Ca}^{2+}$ tran-

sients are reliable indicators of sodium-dependent action potentials. However, when we imaged simultaneously two dendritic sites located near each other, we observed cases in which action potentials reaching both sites triggered $\mathrm{Ca}^{2+}$ transients at a single site only. The behavior did not reflect the presence of a $\mathrm{Ca}^{2+}$ channel hot spot in one of the sites because the mean values were similar at both sites. We favor the hypothesis that at a given moment, one site was inhibited by local interneurons, periglomerular cells in the tuft and granule cells in the basal dendrite. This local synaptic inhibition would be moderate compared with the one evoked by electrical stimulation of a granule cell assemble that was reported to block completely action potential propagation (Xiong and Chen, 2002). The moderate spontaneous synaptic inhibition would attenuate sodium spikes and block highthreshold calcium channels activation, whereas full sodium spikes would be regenerated further. Such a hypothesis is in agreement with the recent results of Lowe (2002) demonstrating in vitro that uncaging GABA locally onto mitral cell basal dendrites can reduce the size of backpropagating action potentials without blocking their farther propagation. Therefore, our method to determine the probability of action potential propagation underestimated the reality, and it is thus conceivable that under urethane anesthesia each evoked action potential systematically reaches all mitral cell dendrodendritic sites. This reliability is in marked contrast with the absence of propagation in the apical dendrite of the frog, a difference that could result from differences in temperature, in anesthesia, or in the density of sodium channels (Delaney et al., 2001).

Considering the case of basal dendrites, our results differ from those of the in vitro study by Margrie et al. (2001) in which action potential size decreased with distance and failed to trigger $\mathrm{Ca}^{2+}$ transients distally. Our results are rather in line with the work of Xiong and Chen (2002) as well as with preliminary data obtained with voltage-dependant sensitive dyes (Djurisic et al., 2001) showing in vitro active propagation of single action potentials at remote locations of mitral cell basal dendrites. Thus, independently of state and tissue differences, single action potentials propagate similarly in basal dendrites both in vitro and in vivo. We propose that for single spikes, the presence of release sites imposes an axonal behavior on all mitral cell dendritic processes.

During $40 \mathrm{~Hz}$ evoked bursts, the fluorescence ratio $\Delta F \mathrm{max} /$ $\Delta F 1$, observed in both apical tuft branchlets and basal dendrites, exhibited a summation sublinearity. The sublinearity could reflect the implication of several mechanisms such as (1) dye saturation, (2) failure of action potentials to trigger $\mathrm{Ca}^{2+}$ channels attributable to the inactivation of voltage-dependent $\mathrm{Ca}^{2+}$ channels or a local recurrent inhibition, and (3) complete failure of action potential propagation attributable to the inactivation of voltage-dependent $\mathrm{Na}^{+}$channels or a local recurrent inhibition. Because we observed cases in which single action potentials did not induce local $\mathrm{Ca}^{2+}$ influx, we hypothesize that measuring $\mathrm{Ca}^{2+}$ transients in our experimental conditions, i.e., during evoked bursts in urethane anesthetized animals, underestimates propagation. The corollary is that either voltage-dependent $\mathrm{Ca}^{2+}$ channels could not follow high-frequency firing or recurrent inhibition modulated local $\mathrm{Ca}^{2+}$ influx but was too weak to block propagation. Activation of excitatory synapses from mitral to periglomerular/granular cells, during an evoked burst, was not efficient enough to trigger all inhibitory synapses from periglomerular/granular cells to mitral cells and block propagation. In vitro, electrical stimulation of granule cells blocks action potential propagation in basal dendrites (Xiong and Chen, 2002). In vivo, however, full recurrent inhibition would require coincident burst 
A

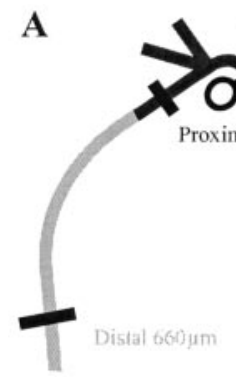

B

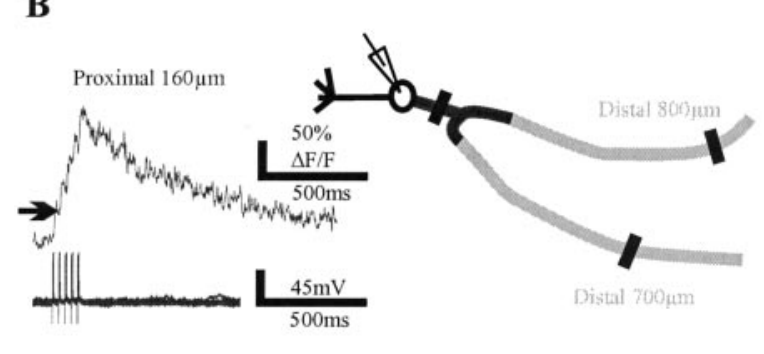

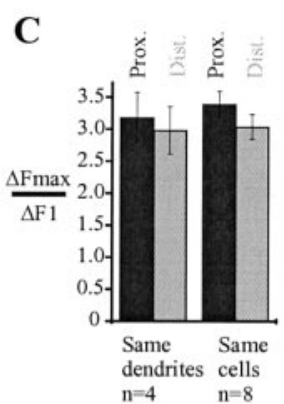

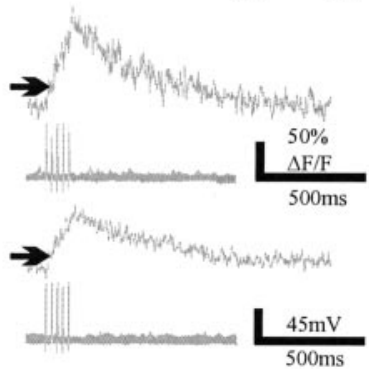

Figure 6. Burst of action potentials backpropagate distally in basal dendrites. A, Left, Superposition of $\mathrm{Ca}^{2+}$ signals evoked by one and five action potentials (interspike interval $=25 \mathrm{msec}$ ) in the proximal (top traces) and distal (bottom traces) parts of a basal dendrite (average of $10-18$ sweeps). The recording electrode was located near the first branching point of the apical dendrite. The summation of fluorescence was sublinear at each site. The sublinearity was not caused by saturation of the dye because the $\mathrm{Ca}^{2+}$ signal could still increase significantly during higher firing frequency, as shown for the most distal measurement. $B$, Another cell in which the amplitude of $\Delta F / F$ differed in two distal branches originating from the same proximal branch. In that case summation was nearly linear. C, Means of $\Delta F \mathrm{max} / \Delta F 1$ recorded in the proximal and distal parts of basal dendrites. Histograms on the left are from four different cells in which measurements were obtained on the same dendritic branch (no branching points in between). Histograms on the right include additional recordings in which branching points were present between the proximal and distal recording sites.

firing of both excitatory and inhibitory cells, an activity that occurs during odor-evoked excitation and that releases $\mathrm{Mg}^{2+}$ block of NMDA receptors from interneurons. Quantitative analysis of $\mathrm{Ca}^{2+}$ increases resulting from odor-evoked bursts would be hazardous, however, in regard to the presence of subthreshold synaptic $\mathrm{Ca}^{2+}$ increases associated with firing (Charpak et al., 2001). Finally, the determination of the weight of recurrent inhibition on dendritic propagation during urethane anesthesia will require the local application of $\mathrm{GABA}_{\mathrm{A}}$ receptor antagonists, a "tour de force" when combined with intracellular recordings and TPLSM imaging of $\mathrm{Ca}^{2+}$, and a result that will have to be revisited in nonanesthetized animals (Mair, 1982).

\section{References}

Aroniadou-Anderjaska V, Zhou FM, Priest CA, Ennis M, Shipley MT (2000) Tonic and synaptically evoked presynaptic inhibition of sensory input to the rat olfactory bulb via GABA(B) heteroreceptors. J Neurophysiol 84:1194-1203.

Bischofberger J, Jonas P (1997) Action potential propagation into the presynaptic dendrites of rat mitral cells. J Physiol (Lond) 504:359-365.

Charpak S, Mertz J, Beaurepaire E, Moreaux L, Delaney K (2001) Odorevoked calcium signals in dendrites of rat mitral cells. Proc Natl Acad Sci USA 98:1230-1234.

Chen WR, Shepherd GM (1997) Membrane and synaptic properties of mitral cells in slices of rat olfactory bulb. Brain Res 745:189-196.

Chen WR, Midtgaard J, Shepherd GM (1997) Forward and backward propagation of dendritic impulses and their synaptic control in mitral cells. Science 278:463-467.

Chen WR, Xiong W, Shepherd GM (2000) Analysis of relations between NMDA receptors and GABA release at olfactory bulb reciprocal synapses. Neuron 25:625-633.

Chen WR, Shen GY, Shepherd GM, Hines ML, Midtgaard J (2002) Multiple modes of action potential initiation and propagation in mitral cell primary dendrite. J Neurophysiol 88:2755-2764.

Colbert CM, Magee JC, Hoffman DA, Johnston D (1997) Slow recovery from inactivation of $\mathrm{Na}^{+}$channels underlies the activitydependent attenuation of dendritic action potentials in hippocampal CA1 pyramidal neurons. J Neurosci 17:6512-6521.

Cox CL, Denk W, Tank DW, Svoboda K (2000) Action potentials reliably invade axonal arbors of rat neocortical neurons. Proc Natl Acad Sci USA 97:9724-9728.

Debarbieux F, Audinat E, Charpak S (2001) Two-photon imaging of action potential propagation in mitral cell dendrites of rat olfactory bulb in vivo. Soc Neurosci Abstr 27:622.11.

Delaney K, Davison I, Denk W (2001) Odourevoked $\left[\mathrm{Ca}^{2+}\right]$ transients in mitral cell dendrites of frog olfactory glomeruli. Eur J Neurosci 13:1658-1672.

Denk W, Strickler JH, Webb WW (1990) Twophoton laser scanning fluorescence microscopy. Science 248:73-76.

Desmaisons D, Vincent JD, Lledo PM (1999) Control of action potential timing by intrinsic subthreshold oscillations in olfactory bulb output neurons. J Neurosci 19:10727-10737.

Djirisic MR, Antic S, Zecevic DP (2001) Voltage-imaging in mitral and tufted neurons of the rat olfactory bulb. Soc Neurosci Abstr 27:623.7.

Friedman D, Strowbridge BW (2000) Functional role of NMDA autoreceptors in olfactory mitral cells. J Neurophysiol 84:39-50.

Hamilton KA, Kauer JS (1985) Intracellular potentials of salamander mitral/tufted neurons in response to odor stimulation. Brain Res 338:181-185.

Hausser M, Spruston N, Stuart GJ (2000) Diversity and dynamics of dendritic signaling. Science 290:739-744.

Helmchen F, Svoboda K, Denk W, Tank DW (1999) In vivo dendritic calcium dynamics in deep-layer cortical pyramidal neurons. Nat Neurosci 2:989-996.

Hoffman DA, Magee JC, Colbert CM, Johnston D (1997) $\mathrm{K}^{+}$channel regulation of signal propagation in dendrites of hippocampal pyramidal neurons. Nature 387:869-875.

Isaacson JS (2001) Mechanisms governing dendritic gamma-aminobutyric acid (GABA) release in the rat olfactory bulb. Proc Natl Acad Sci USA 98:337-342.

Isaacson JS, Strowbridge BW (1998) Olfactory reciprocal synapses: dendritic signaling in the CNS. Neuron 20:749-761.

Jahr CE, Nicoll RA (1980) Dendrodendritic inhibition: demonstration with intracellular recording. Science 207:1473-1475.

Kaba H, Hayashi Y, Higuchi T, Nakanishi S (1994) Induction of an olfactory memory by the activation of a metabotropic glutamate receptor. Science 265:262-264.

Kirillova V, Lin JW (1998) A whole-cell clamp study of dendrodendritic synaptic activities in mitral cells of turtle olfactory bulb slices. Neuroscience 87:255-264.

Larkum ME, Zhu JJ, Sakmann B (1999) A new cellular mechanism for coupling inputs arriving at different cortical layers. Nature 398:338-341.

Lowe G (2002) Inhibition of backpropagating action potentials in mitral cell secondary dendrites. J Neurophysiol 88:64-85.

Mair RG (1982) Response properties of rat olfactory bulb neurones. J Physiol (Lond) 326:341-359.

Maravall M, Mainen ZF, Sabatini BL, Svoboda K (2000) Estimating intracellular calcium concentrations and buffering without wavelength ratioing. Biophys J 78:2655-2667.

Margrie TW, Sakmann B, Urban NN (2001) Action potential propagation in mitral cell lateral dendrites is decremental and controls recurrent and lateral inhibition in the mammalian olfactory bulb. Proc Natl Acad Sci USA 98:319-324.

Markram H, Lubke J, Frotscher M, Sakmann B (1997) Regulation of synap- 
tic efficacy by coincidence of postsynaptic APs and EPSPs. Science 275:213-215.

Meredith M (1986) Patterned response to odor in mammalian olfactory bulb: the influence of intensity. J Neurophysiol 56:572-597.

Mori K, Takagi SF (1978) An intracellular study of dendrodendritic inhibitory synapses on mitral cells in the rabbit olfactory bulb. J Physiol (Lond) 279:569-588.

Nakamura T, Barbara JG, Nakamura K, Ross WN (1999) Synergistic release of $\mathrm{Ca}^{2+}$ from IP3-sensitive stores evoked by synaptic activation of mGluRs paired with backpropagating action potentials. Neuron 24:727-737.

Pare D, Shink E, Gaudreau H, Destexhe A, Lang EJ (1998) Impact of spontaneous synaptic activity on the resting properties of cat neocortical pyramidal neurons in vivo. J Neurophysiol 79:1450-1460.

Rall W, Shepherd GM, Reese TS, Brightman MW (1966) Dendrodendritic synaptic pathway for inhibition in the olfactory bulb. Exp Neurol 14:44-56.

Salin PA, Lledo PM, Vincent JD, Charpak S (2001) Dendritic glutamate autoreceptors modulate signal processing in rat mitral cells. J Neurophysiol 85:1275-1282.

Schiller J, Schiller Y, Clapham DE (1998) NMDA receptors amplify calcium influx into dendritic spines during associative pre- and postsynaptic activation. Nat Neurosci 1:114-118.

Schoppa NE, Kinzie JM, Sahara Y, Segerson TP, Westbrook GL (1998) Dendrodendritic inhibition in the olfactory bulb is driven by NMDA receptors. J Neurosci 18:6790-6802.

Shepherd GM (1999) Information processing in dendrites. In: Fundamental neuroscience (Zigmond MJ, Bloom FE, Landis SE, Roberts JL, Squire LR, eds), pp 363-388. San Diego: Academic.
Spruston N, Schiller Y, Stuart G, Sakmann B (1995) Activity-dependent action potential invasion and calcium influx into hippocampal CA1 dendrites. Science 268:297-300.

Stuart G, Spruston N, Sakmann B, Hausser M (1997) Action potential initiation and backpropagation in neurons of the mammalian CNS. Trends Neurosci 20:125-131.

Svoboda K, Denk W, Kleinfeld D, Tank DW (1997) In vivo dendritic calcium dynamics in neocortical pyramidal neurons. Nature 385:161-165.

Svoboda K, Helmchen F, Denk W, Tank DW (1999) Spread of dendritic excitation in layer $2 / 3$ pyramidal neurons in rat barrel cortex in vivo. Nat Neurosci 2:65-73.

Tsubokawa H, Ross WN (1996) IPSPs modulate spike backpropagation and associated $\left[\mathrm{Ca}^{2+}\right]_{\mathrm{i}}$ changes in the dendrites of hippocampal CA1 pyramidal neurons. J Neurophysiol 76:2896-2906.

Tsubokawa H, Ross WN (1997) Muscarinic modulation of spike backpropagation in the apical dendrites of hippocampal CA1 pyramidal neurons. J Neurosci 17:5782-5791.

Wellis DP, Scott JW, Harrison TA (1989) Discrimination among odorants by single neurons of the rat olfactory bulb. J Neurophysiol 61:1161-1177.

Xiong W, Chen WR (2002) Dynamic gating of spike propagation in the mitral cell lateral dendrites. Neuron 34:115-126.

Yokoi M, Mori K, Nakanishi S (1995) Refinement of odor molecule tuning by dendrodendritic synaptic inhibition in the olfactory bulb. Proc Natl Acad Sci USA 92:3371-3375.

ZilberterY (2000) Dendritic release of glutamate suppresses synaptic inhibition of pyramidal neurons in rat neocortex. J Physiol (Lond) 528:489-496.

Zilberter Y, Kaiser KM, Sakmann B (1999) Dendritic GABA release depresses excitatory transmission between layer $2 / 3$ pyramidal and bitufted neurons in rat neocortex. Neuron 24:979-988. 